\title{
Regression of orbital brown tumor after surgical removal of parathyroid adenoma
}

Felipe Martins de Oliveira', Tiago Eidy Makimoto', Nilza Maria Scalissi', Marília Martins Silveira Marone', Sergio Setsuo Maeda'

\section{SUMMARY}

Brown tumors are rare skeletal manifestations that occur in less than $2 \%$ of primary hyperparathyroidism (PHPT) cases. Even rarer is the occurrence of brown tumor of the orbit, and few cases have been reported around the world. The rare instance of this benign tumor has prompted us to report the case and treatment of an orbital brown tumor in a patient with PHPT caused by parathyroid adenoma. We present the case of a patient undergoing follow-up at a referral center. The 60-year-old female patient, presented herself with progressive swelling in the nasal region, epistaxis and proptosis, she had noticed seven months prior to our examination. Multiple imaging and laboratory findings revealed parathyroid hormone (PTH)-dependent hypercalcemia (total calcium $=14.3 \mathrm{mg} / \mathrm{dL}$ and PTH $=1,573$ $\mathrm{pg} / \mathrm{mL}$ ), a nodular lesion in the upper pole of the left thyroid lobe and increased uptake in left upper cervical region. The patient underwent left superior parathyroidectomy in September 2011, which led to the normalization of hypercalcemia and regression of the orbital tumor, as seen on control CT scan. This case highlights the spontaneous regression of the brown tumor after surgical management of the parathyroid adenoma. Arch Endocrinol Metab. 2015;59(5):455-9

${ }^{1}$ Irmandade da Santa Casa de Misericórdia de São Paulo (ISCMSP), Departamento de Medicina, Disciplina de Endocrinologia e Metabologia, São Paulo, SP, Brazil

Correspondence to: Felipe Martins de Oliveira Rua Professora Maria José Ferreira, 166 19910-075 - Ourinhos, SP, Brazil femaoll@yahoo.com.br fmo.endocrinologia@gmail.com

Received on July/1/2014 Accepted on Dec/1/2014

\section{CASE REPORT}

W e report the case of D.O., a 60-year-old female patient, born and raised on Itaparica Island in Bahia, Brazil, who sought the Department of Otorhinolaryngology at the Santa Casa de São Paulo Hospital in 2011 with progressive swelling in the nasal region, frequent epistaxis and proptosis she had noticed seven months prior to our examination. The patient complained of polyuria, constipation and chronic fatigue, symptoms that coincided with mass growth. The patient denied weight loss or history of renal colic or fractures. On physical examination, no palpable cervical masses were noted.

A CT scan of the paranasal sinuses performed on August, 2011 (Figure 1), revealed a $8.1 \times 6 \times 5.1 \mathrm{~cm}$ solid mass in the left nasal cavity. Total obstruction of the structure, deformity of the superior and lateral portions of the nasal pyramid, and marked concavity of the medial wall of the maxillary antrum and left orbital floor were observed. The entire lesion showed intense heterogeneous enhancement after contrast infusion. Further investigation also revealed "salt and pepper" appearance of the skull (as seen at plain X-ray in Figure 2).
Biopsy of the nasal cavity lesion performed on August, 2011, proved it to be a proliferative process with unevenly distributed multinucleated giant cells, fibroblastic stroma, hemorrhage and hemosiderin-laden macrophages, with no evidence of malignancy. Histopathological findings were indicative of giant cell tumor, reparative granuloma and hyperparathyroidism.

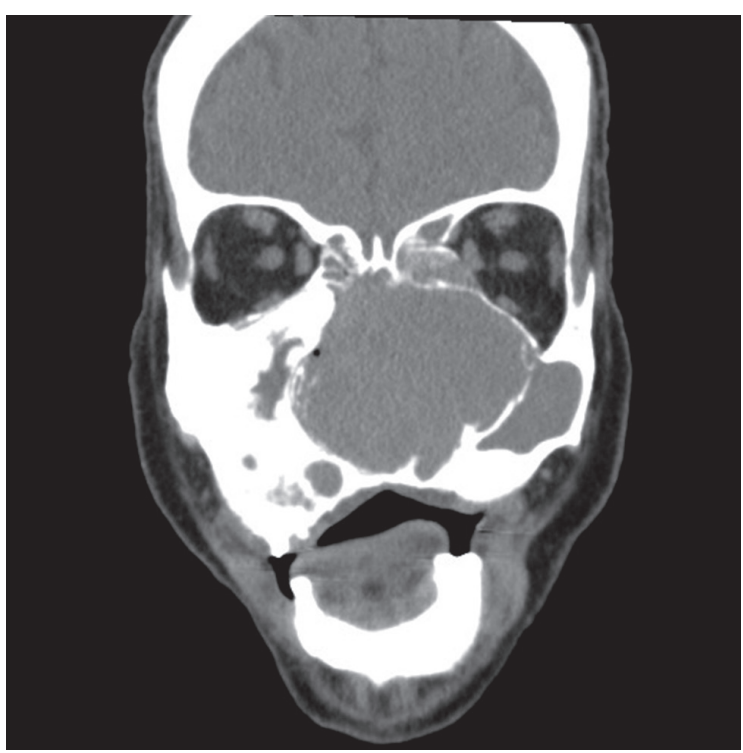

Figure 1. Coronal CT scan shows large mass in left nasal cavity. 


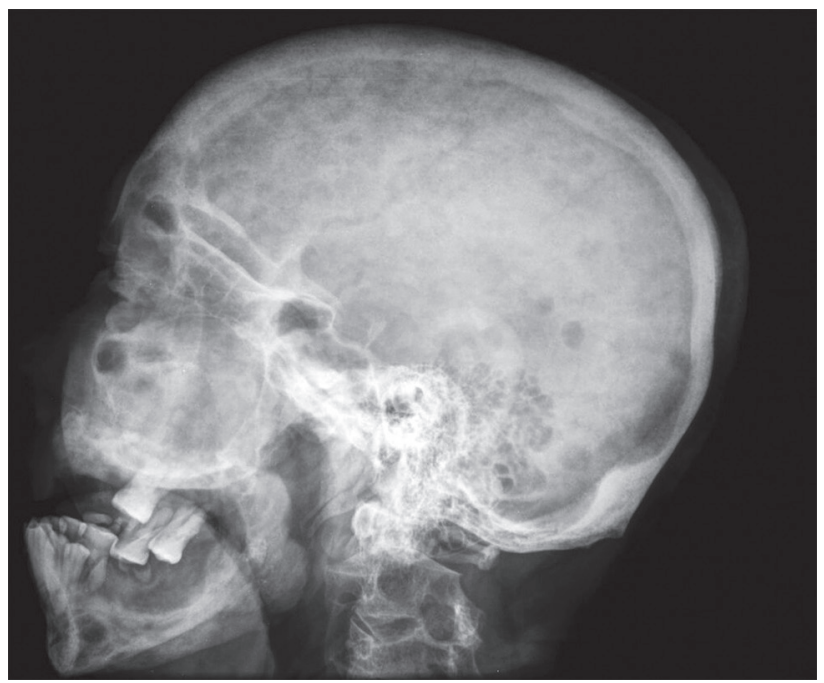

Figure 2. Plain X-ray exhibiting "salt and pepper" appearance of the skull.

Based on the results of the biopsy, tests were carried out as described in table 1. The patient was then referred to Endocrinology Section with a suspicion of primary hyperparathyroidism. Ultrasonography of the kidneys and urinary tract revealed loss of corticomedullary differentiation, preserved renal volume and bilateral multiple hyperechoic foci throughout the parenchyma (consistent with calcifications). No signs of renal or ureteral lithiasis were found. Osteoporosis was later detected by bone density testing (August, 2011), with dual-energy X-ray absorptiometry (DXA - LUNAR Prodigy - GE) (Table 2).

Cervical ultrasonography performed on the patient to locate the parathyroid tumor, revealed a nonspecific mass in the left tracheoesophageal groove, consistent with a level VI lymph node, and enlargement of parathyroid and extraglandular thyroid tissue. Supplemen-

Table 1. Patient's pre- and postoperative laboratory tests

\begin{tabular}{lcc}
\hline Test & Preoperative & Postoperative \\
\hline $\begin{array}{l}\text { Serum calcium } \\
\text { (RR*: } 8.6-10.0 \mathrm{mg} / \mathrm{dL} \text { )\# }\end{array}$ & 13.6 & 8.3 \\
$\begin{array}{l}\text { Parathormone } \\
\text { (RR: } 14-72 \mathrm{pg} / \mathrm{mL})^{\star *}\end{array}$ & 1,573 & 97 \\
Alkaline phosphatase & 2,050 & \\
(RR: $70-290 \mathrm{U} / \mathrm{L}) \#$ & & 66 \\
$\begin{array}{l}\text { Phosphorus } \\
\text { (RR: } 2.8-4.1 \mathrm{mg} / \mathrm{dL}) \#\end{array}$ & 2.2 & --- \\
Creatinine & & \\
(RR: $0.6-1.3 \mathrm{mg} / \mathrm{dL}) \#$ & 0.9 & --- \\
25-hydroxyvitamin D & & \\
(RR: $>30 \mathrm{ng} / \mathrm{mL})^{* *}$ & --- & 46.8
\end{tabular}

\# Colorimetric assay. * RR: reference range. ${ }^{* *}$ Chemiluminescent assay (IMMULITE 2000, Siemens). tary CT scan of the neck showed a $3.8 \times 1.4 \times 1 \mathrm{~cm}$ nodule in the upper pole of the left thyroid lobe. A sestamibi parathyroid scan (Figure 3) showed increased uptake in the upper left cervical region.

Table 2. Patient's bone mineral density evolution

\begin{tabular}{|c|c|c|c|c|}
\hline \multirow[t]{2}{*}{ Region } & \multicolumn{2}{|c|}{ August/2011 } & \multicolumn{2}{|c|}{ January/2013 } \\
\hline & $\begin{array}{l}\text { BMD* }^{*} \\
\left(\mathrm{~g} / \mathrm{cm}^{2}\right)\end{array}$ & $\begin{array}{l}\text { T-score } \\
(\text { SD**) }\end{array}$ & $\begin{array}{l}\text { BMD* }^{*} \\
\left(\mathrm{~g} / \mathrm{cm}^{2}\right)\end{array}$ & $\begin{array}{l}\text { T-score } \\
\left(\text { SD**) }^{\star *}\right.\end{array}$ \\
\hline $\begin{array}{l}\text { Lumbar spine } \\
\text { (L1 - L4) }\end{array}$ & 0.851 & -2.8 & 0.975 & -1.8 \\
\hline Femoral neck & 0.815 & -1.6 & 0.988 & -0.4 \\
\hline Total femur & 0.834 & -1.4 & 0.980 & -0.2 \\
\hline
\end{tabular}

* BMD: bone mineral density. ${ }^{* \star}$ SD: standard deviation.

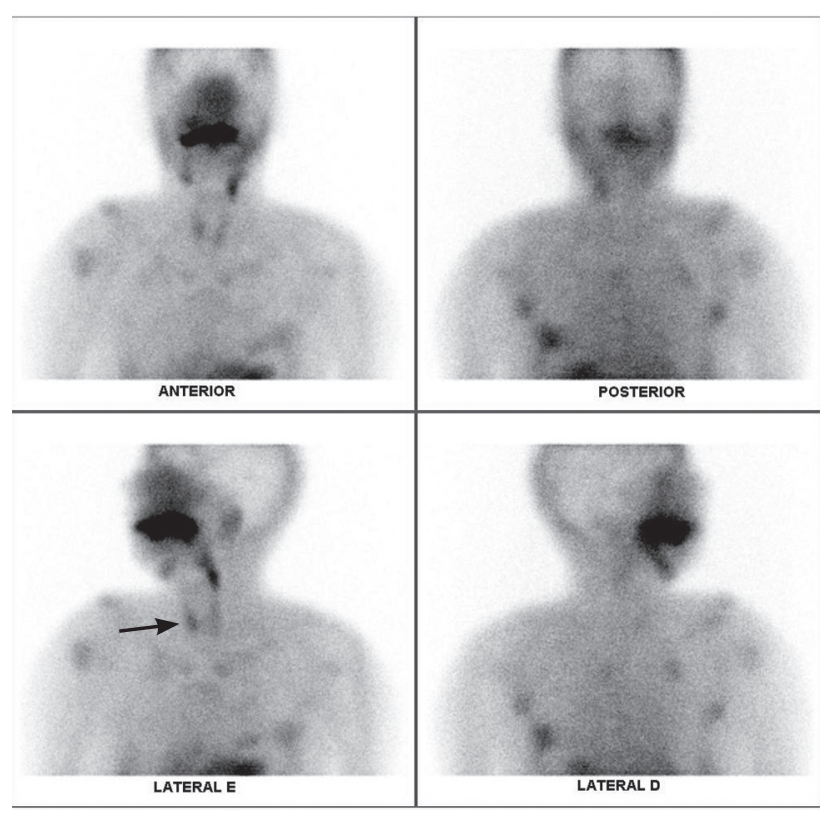

Figure 3. Sestamibi scintigraphy showing increased uptake in left superior parathyroid gland.

The patient underwent left superior parathyroidectomy on September, 2011. Histopathological examination confirmed monomorphic proliferation of chief cells, without atypia, arranged in insular and pseudoacinar pattern, suggestive of parathyroid adenoma. Lymph node resection was not performed.

A significant decline in serum calcium concentration was observed. On her last follow-up examination, the patient was on $1,500 \mathrm{mg} /$ day of calcium carbonate, 25 $\mathrm{mg}$ /day of hydrochlorothiazide and 20,000 UI/week of cholecalciferol. The last bone mineral densitometry (January, 2013) exhibited improvement in bone mass, as seen in table $2(+15 \%$ in Ll-L4 and $+18 \%$ in to- 
tal femur). Another CT scan of the sinuses (October, 2013), revealed spontaneous regression of the brown tumor (Figure 4).

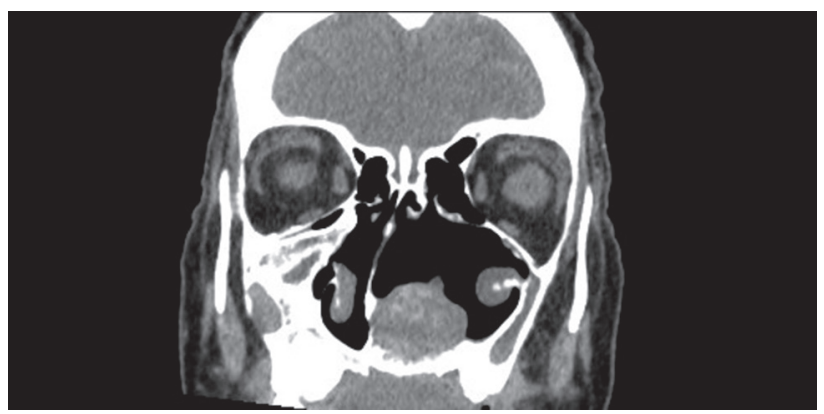

Figure 4. Coronal CT scan shows reduced orbital tumor.

\section{Study approval}

This report was approved by the Santa Casa de São Paulo Ethics Committee.

\section{DISCUSSION}

Hyperparathyroidism may be primary, secondary or tertiary. Primary hyperparathyroidism (PHPT) is the most common cause of hypercalcemia in ambulatory patients (1-3) and accounts for 0.1 to $1 \%$ of population (inpatients and outpatients) in the United States and Europe, with an incidence of 30-150 cases per 100,000 people per year (4).

The most common cause of PHPT is a parathyroid adenoma $(>80 \%)$. The remaining cases are due to hyperplasia of the parathyroid gland, or parathyroid carcinoma in less than $0.5 \%$ of cases (5). Most cases of primary hyperparathyroidism are sporadic, but there is a higher incidence in patients with a history of exposure to neck irradiation, and approximately $5 \%$ of cases are familial (6).

Other possible causes of hypercalcemia must be considered in the diagnosis of PHPT. Differential diagnosis should include other conditions that cause osteoporosis, nephrocalcinosis, hypophosphatemia, and hypercalcemia of malignancy. The diagnosis of PHPT is confirmed by demonstrating persistent hypercalcemia or normal-high serum calcium levels in the presence of elevated or inappropriately normal parathyroid hormone $(\mathrm{PTH})$ concentrations and histological evidence of parathyroid adenoma or hyperplasia (7).

Although many systems are affected in primary hyperparathyroidism, the most pronounced alternations are observed in the bone (8). However, as a result of the introduction of routine serum calcium measurements in developed countries, PHPT has evolved to a disorder that is asymptomatic in most patients.

Long-term increased secretion of PTH enhances bone mobilization through rapid osteoclast turnover and contributes to the formation of brown tumors, also called osteitis fibrosa cystica (a reparative cellular process and not a true neoplasm), which commonly affects the ribs, clavicle, tibia, femur and pelvic girdle $(5,9)$. The term brown tumor is derived from the characteristic appearance of brownish material within the cystic lesion. This appearance is due to blood pigments that are both free and within hemosiderin-laden macrophages (10).

Skeletal manifestations in the form of brown tumors are rare and occur in less than $2 \%$ of cases of primary hyperparathyroidism $(11,12)$, but more predominantly in secondary hyperparathyroidism. Brown tumors have rarely been described as involving the orbital and maxillofacial bones, and few cases have been reported around the world $(6,8)$. Due to the paucity of reports describing the atypical location of brown tumors, we feel it is of interest to compare data compiled previously with what we report in this article. Bahrami and cols. (10) summarized a series of 15 cases of brown tumors in facial bones reported up to 2010, and concluded that brown tumors arise more frequently in the mandible than in maxilla, are caused mainly by secondary HPT (8 patients, whereas only 6 cases were diagnosed with PHPT and one with tertiary hyperparathyroidism), affect more women than men (13 female patients compared to only 2 male patients) and are most common in individuals aged between 20 and 50 years old $(8$ cases).

Over 70 different benign, malignant and pseudo nasosinusal tumors, have been described and considered in the differential diagnosis of brown tumors in facial bones. Despite histological variety, approximately $0.8 \%$ of all human cancers are located in the nasosinusal area, representing less than $3 \%$ of head and neck cancers. Tumors in this region usually cause unspecific and common symptoms. Unilateral nasal obstruction, epistaxis, facial pain and local infection are the most common reported initial symptoms (13). Patients with brown tumors in the orbit may have a mass, proptosis, pain, diplopia, decreased extraocular motility or decreased visual acuity (14). Given the rarity of these tumors, lack of symptom specificity and the wide range of differential diagnoses, advanced imaging studies and precise anatomopathological analysis play a crucial role in the proper management of each case (13). 
Differential diagnoses for nasosinusal tumors includes: osteoma [most frequent benign tumor of the paranasal sinuses (15)], stesioneuroblastoma, giant cells central granuloma, extramedullary plasmocytoma, angiomatoid lesions (glomangioma and nasosinusal hemangiopericytoma), neurofibroma, cement-ossifying fibroma (13,16,17), osteoblastoma and metastasis (14).

Computed tomography is very important in the evaluation of bone extension of the tumor and also the site of origin (15). As most giant cell lesions of the bone share similar histological features, brown tumors must be differentiated from other lytic lesions such as giant cell tumors (GCT), reparative granulomas and aneurysmal bone cysts $(\mathrm{ABC})$. Giant cell reparative granulomas consist of multinucleated osteoclast-like giant cells, fibrous tissue and reactive bone in a zonal pattern, frequently associated with extravasated red blood cells (18). In turn, solid ABC have a great fibroblastic, osteoblastic and osteoclastic compound (16). Because the histology of both GCT and ABC may closely mimic that of brown tumors, further investigation of giant cell lesions must include accurate measurement of serum calcium, phosphorus, alkaline phosphatase and PTH levels.

Most authors agree that brown tumors tend to regress spontaneously after diagnosis and treatment of the underlying disease (hyperparathyroidism) (19), with substantial involution of facial lesions within 6 months of successful parathyroidectomy, eliminating the need for surgical removal of the facial tumor. This was the case with our patient who had brown tumor remission after surgical resection of the affected parathyroid. Although surgical resection of brown tumors may not be necessary, biopsy of the tumor is a crucial and essential step to exclude malignancy and other bone diseases, and appears to be indispensable to avoid unnecessary extensive operation $(20,21)$.

In general, brown tumors accompanied by severe hypercalcemia and significantly elevated PTH levels, as those presented above, are suggestive of parathyroid carcinoma $(22,23)$, a rare malignancy, with a reported incidence of less than $1 \%$ of primary hyperparathyroidism cases (22-25). Unlike benign primary hyperparathyroidism, which is more common in women; parathyroid carcinoma afflicts men and women equally, and the age of presentation is earlier than the mean age of patients with benign PHPT (22-25), with frequent symptoms of renal and skeletal involvement, and palpable neck mass (23-25).
Anatomopathological criteria of malignancy alone do not make an accurate distinction between primary hyperparathyroidism due to adenoma or carcinoma. (22). Under macroscopic analysis, malignancy should be considered when: tumors are greater than $1.5 \mathrm{~cm}$ in diameter $(22)$ - or greater than $3-4 \mathrm{~cm}$, according to other authors (23), there is adherence to adjacent tissues $(22,23,26)$ and invasion of ipsilateral thyroid gland, strap muscles, ipsilateral recurrent laryngeal nerve, esophagus and trachea $(22,23)$. The principal histologic features that distinguish parathyroid carcinoma from adenoma, identified by Schantz and Castleman were the presence of mitosis within parenchymal cells, fibrous trabeculae including often thick fibrous bands, and capsular and vascular invasion $(22,24-26)$. Despite all these criteria, eventually, the only unequivocal proof of malignancy is the absence of postoperative remission (22) or the presence of metastases (22,24-26).

It is important to highlight that in cases of palpable disease or obvious mass, fine needle aspiration is not usually recommended. This is due to the extreme difficulty of differentiating between benign and malignant disease on cytology, in addition to the potential for seeding of tumor cells (24).

Changes in bone mineral density (BMD) following surgical cure in patients with severe disease are usually remarkable (27), and are most significant during the first year after parathyroidectomy, when the greatest gains tend to occur (28). On the other hand, patients with asymptomatic disease show a mean increment in BMD of 2.9 to $10 \%$ at the lumbar spine and 4.1 to $8 \%$ at the femoral neck in 5 years (27). Thus as a general rule, one might infer that, the greater the bone disease, the greater the likelihood that bone mass will improve postoperatively $(28,29)$.

It is likely that the postoperative changes in BMD represent a true anabolic effect (28), the result of this postoperative transient phase of uncoupling of the two processes (postoperative bone resorption and bone formation) results in an "anabolic window" characterized by the refilling of the enlarged remodeling space and the subsequent matrix mineralization (30). In many cases, however, reversal of bone loss is not complete (28).

In conclusion, we have presented a report describing the diagnosis, treatment and positive outcome of a rare orbital brown tumor case based on current understanding of primary hyperparathyroidism and that was essential for a satisfactory evolution. 
Acknowledgements: the authors thank Nuclimagem laboratory for providing tests performed by this patient during her follow-up.

Funding support: there was no funding source for this project.

Disclosure: no potential conflict of interest relevant to this article was reported.

\section{REFERENCES}

1. Khan AA. Medical management of primary hyperparathyroidism. J Clin Densitom. 2013;16(1):60-3.

2. Pallan S, Khan A. Primary hyperparathyroidism: Update on presentation, diagnosis, and management in primary care. Can Fam Physician. 2011;57(2):184-9.

3. DeLellis RA. Parathyroid tumors and related disorders. Mod Pathol. 2011;24 Suppl 2:S78-93.

4. Mundy GR, Cove DH, Fisken R. Primary hyperparathyroidism: changes in the pattern of clinical presentation. Lancet. 1980;1(8182):1317-20.

5. Sia HK, Hsieh MC, Yang LH, Tu ST. Maxillary brown tumor as initial presentation of parathyroid adenoma: a case report. Kaohsiung J Med Sci. 2012;28(7):400-3.

6. Mackenzie-Feder J, Sirrs S, Anderson D, Sharif J, Khan A. Primary hyperparathyroidism: an overview. Int J Endocrinol. 2011; 2011:251410.

7. Girish P, Lala M, Chadha M, Shah NF, Chauhan PH. Study of primary hyperparathyroidism. Indian J Endocrinol Metab. 2012;16(Suppl 2):S418-20.

8. Mantar F, Gunduz S, Gunduz UR. A reference finding rarely seen in primary hyperparathyroidism: brown tumor. Case Rep Med. 2012;2012.

9. Ullah E, Ahmad M, Ali SA, Redhu N. Primary hyperparathyroidism having multiple Brown tumors mimicking malignancy. Indian J Endocrinol Metab. 2012;16(6):1040-2.

10. Bahrami E, AlirezaT, Ebrahim H, Mohammadreza S. Maxillary and orbital brown tumor of primary hyperparathyroidism. Am J Case Rep. 2012;13:183-6.

11. Silverberg SJ, Bilezikian JP. Evaluation and management of primary hyperparathyroidism. J Clin Endocrinol Metab. 1996;81(6):2036-40.

12. Parrish CM, O'Day DM. Brown tumor of the orbit. Case report and review of the literature. Arch Ophtalmol. 1986;104(8):1199-202.

13. Araújo RP, Gomes EF, Menezes DB, Ferreira LMBM, Rios ASN. Rare nasosinusal tumors: case series and literature review. Rev Bras Otorrinolaringol. 2008;74(2):307-14.
14. Monteiro ML. Multiple brown tumors of the orbital walls: case report. Arq Bras Oftalmol. 2009;72(1):116-8.

15. Kayaci S, Kanat A, Gucer H, Seckin H. Primary osteoma of the orbit with atypical facial pain: case report and literature review. Turk Neurosurg. 2012;22(3):389-92.

16. Calleja JMLA, Carretero JLC, Martín JG, Burgueño M. Aneurysmal bone cyst of the mandible: case presentation and review of the literature. Med Oral Patol Oral Cir Bucal. 2007;12:E401-3.

17. Suarez-Soto A, Baquero-Ruiz de la Hermosa MC, Minguez-Martínez I, Floría-García LM, Barea-Gámiz J, Delhom-Valero J, et al. Management of fibro-osseous lesions of the craniofacial area. Presentation of 19 cases and review of the literature. Med Oral Patol Oral Cir Bucal. 2013;18(3):e479-85.

18. McCarthy EF. Fibro-osseus lesions of the maxillofacial bones. Head Neck Pathol. 2013;7(1):5-10.

19. Naiman J, Green WR, d'Heurle D, lliff WJ, Benedict GW, Eggleston $\mathrm{JC}$, et al. Brown tumor of the orbit associated with primary hyperparathyroidism. Am J Ophthalmol. 1980;90(4):565-71.

20. Al-Gahtany M, Cusimano M, Singer W, Bilbao J, Kovacs K, MarottaT. Brown tumors of the skull base. Case report and review of the literature. J Neurosurg. 2003;98(2):417-20.

21. Emin $A H$, Süog\#lu $Y$, Demir D, Karatay MC. Normocalcemic hyperparathyroidism presented with mandibular brown tumor: report of a case. Auris Nasus Larynx. 2004;31(3):299-304.

22. Vieira JGH, Ohe MN, Hauache OM, de Oliveira UM, Delana JM, Gonçalves A, Lazaretti-Castro M. Carcinoma de paratireoide. Arq Bras Endocrinol Metab. 2005;49(5):811-5.

23. Lumachi F, Basso SM, Basso U. Parathyroid cancer: etiology, clinical presentation and treatment. Anticancer Res. 2006;26(6C):48037.

24. Givi B, Shah JP. Parathyroid carcinoma. Clin Oncol (R Coll Radiol). Clin Oncol (R Coll Radiol). 2010;22(6):498-507.

25. Marcocci C, Cetani F, Rubin MR, Silverberg SJ, Pinchera A, Bilezikian JP. Parathyroid carcinoma. J Bone Miner Res. 2008;23(12):1869-80.

26. Sharretts JM, Kebebew E, Simonds WF. Parathyroid cancer. Semin Oncol. 2010;37(6):580-90.

27. Bandeira F, Griz L, Caldas G, Bandeira C, Freese E. From mild to severe primary hyperparathyroidism: the Brazilian experience. Arq Bras Endocrinol Metabol. 2006;50(4):657-63.

28. Kulak CA, Bandeira C, Voss D, Sobieszczyk SM, Silverberg SJ, Bandeira $F$, et al. Marked improvement in bone mass after parathyroidectomy in osteitis fibrosa cystica. J Clin Endocrinol Metab. 1998;83(3):732-5.

29. Bandeira F, Cusano NE, Silva BC, Cassibba S, Almeida CB, Machado VCC, et al. Bone disease in primary hyperparathyroidism. Arq Bras Endocrinol Metab. 2014;58(5):553-561.

30. Marcocci C, Cianferotti L, Cetani F. Bone disease in primary hyperparathyroidism. Ther Adv Musculoskelet Dis. 2012;4(5):357-68. 